\title{
Caminhos e descaminhos da nacionalização do Exército brasileiro no período Regencial (1831-1840).
}

Trials and Errors in the Nationalization of Brazilian Army during the Regental Period (1831-1840)

Fabiana Mehl Sylvestre Rodrigues

Mestranda pelo Programa de

Pós-Graduação em História da

Universidade Federal do Paraná

\section{Resumo}

Neste artigo analisamos algumas das clivagens existentes dentro da elite política e da alta cúpula de oficiais do Exército brasileiro no que concerne à elaboração e consecução de projetos distintos de "nacionalização" das Forças de $1^{\text {a }}$ Linha. Mediante tal análise, é possível perceber que ao mesmo tempo em que se gestavam, no país, os dois principais partidos políticos do Império, também nasciam diferentes opiniões acerca do papel das Forças Armadas no cenário nacional, que se expressaram em propostas distintas de ruptura com alguns aspectos próprios do Antigo Regime Português ainda presentes na instituição militar ao longo do Período Regencial (1831-1840).

\begin{abstract}
In this article we analyze the dissensions that existed not only among the political elite but also among Brazilian Army's high officers concerning the elaboration and execution of distinct regular troops "nationalization" plans. This analysis enables the perception that the gestation of the country's two main political parties was simultaneous to the birth of different opinions about the Armed Forces' role in the national scene, which have been expressed in different proposals of rupture towards some aspects peculiar to the Portuguese Ancien Régime still present in the military institution during the Regency period (1831-1840).
\end{abstract}

Palavras-chaves

Exército, modernização, Regência

Keywords

army, modernization, Regency 
Manoel da Fonseca Lima e Silva nasceu no Rio de Janeiro, em 10 de junho de 1793, assentou praça de cadete em 1805, e foi promovido a alferes em 1808. Cursou a Academia Militar do Rio de Janeiro. Distinguiu-se em diversas campanhas, como contra os revolucionários pernambucanos em 1817, pela Independência na Bahia, e na Cisplatina em 1828. Chegou ao posto de marechal de campo, e ocupou o Ministério da Guerra por duas vezes - em 1831 e em 1835, a convite do Regente Feijó. Em 1854 foi agraciado com o título de Barão de Suruí. Faleceu em $1^{\circ}$ de Abril de 1869. Era tio do futuro Duque de Caxias. A este respeito ver: LOPES, Theodorico e TORRES, Gentil. Ministros da Guerra do Brasil 1808-1945. Rio de Janeiro: Sem Editora, 1946, p. 56.

SILVA, Manoel da Fonseca Lima e. Proposta para o ano de 1831 da administração do Ministério da Guerra apresentada na Augusta Câmara dos Senhores Deputados na Sessão de 1832. Rio de Janeiro: Tipografia Patriótica D' Asttea, 1832, pp. 1-2.

3 LOPES, T. e TORRES, G. Op. Cit. p. 56.

\section{4}

Atas da Câmara dos Deputados, sessão de 16 de julho de 1831. In: CALDEIRA, Jorge (Org.) Diogo Antônio Feijó. São Paulo: Editora 34 Ltda, 1999, p. 76.

5

IZECKSOHN, Vitor. O Cerne da discórdia: a Guerra do Paraguai e o Núcleo Profissional do Exército Brasileiro. Rio de Janeiro: Biblioteca do Exército, 1997, p. 65.

6

Desconhecemos sua origem e ano de nascimento. Chefe militar português, que começou a assumir relevo ao aderir ao lado brasileiro nas lutas de Independência no Maranhão. Lutou também na debelação da Confederação do Equador. Em 1829 foi agraciado com o título de Barão de Itapicurú-Mirim. Ver: LOPES, T. e TORRES, G. Op. Cit. p. 59.

\section{7}

BORGES, José Felix Pinto. Relatório da Repartição dos Negócios da Guerra, apresentado à Assembléia Geral Legislativa na sessão ordinária de 1835 pelo respectivo Ministro e Secretário de Estado. Rio de Janeiro: Tipografia Nacional, 1835, p. 5.

8

Estes números estão presentes em: SHULZ, John. O Exército na Politica: origens da intervenção militar 1850-1894. São Paulo: Edusp, 1994 , p. 216

\section{Introdução}

Em 1832, o Coronel Manoel da Fonseca Lima e Silva'1, então ministro da guerra, enviava para a Câmara dos Deputados a proposta do governo para a fixação das forças de terra para o ano financeiro de 1833 a 1834 2. Um dos elementos mais relevantes deste documento, era a ampla redução de efetivos militares, aspecto que tomara corpo, efetivamente, desde julho de 1831, isto é, desde o momento em que Lima e Silva havia assumido o referido ministério. Conforme se observa em uma obra dedicada a tecer biografias de ministros da guerra brasileiros, sua ascensão aquele gabinete significou "uma remodelação ministerial provocada pelos acontecimentos de 12 a 14 desse mesmo mês, quando elementos do chamado Partido Exaltado incitaram à revolta vários corpos de guarnição da Corte" 3 . A gravidade destes eventos, bem como a impotência do governo frente aos rebeldes, fica bastante evidente em uma declaração do Padre Diogo Antônio Feijó, Ministro da Justiça naquele momento:

A insubordinação de uma parte do corpo da polícia deu ocasião a reunir-se a tropa toda da capital no Campo de Honra, onde até hoje se conserva e consta que dirigem ao governo exigências extraordinárias. $A$ cidade está submergida no terror. Consta-me, não oficialmente, que os perversos em vários pontos tem já cometido assassinios, roubos etc. As Guardas Municipais recolheram-se amedrontadas, e porque se achavam mal armadas e sem disciplina, não podem servir para estabelecer a ordem ${ }^{4}$.

De acordo com o historiador Vitor Izecksohn, um observador contemporâneo relatava por aqueles dias que o Exército "que tomara parte ativa no processo de abdicação de Pedro I, estava de tal modo entregue às 'mil direções da insubordinação' que não tinha sequer a unidade necessária para poder dar uma autoridade à revolução vencedora"5. Poucos anos depois, o general José Félix Pereira Pinto Borges ${ }^{6}$, ministro da guerra em 1835, declarava que "as doutrinas que tem querido levar o espírito do partido político até o alojamento do soldado" estavam fazendo dessa "mesma força armada um dos elementos que devem atualmente concorrer para a confusão e desordem com que estamos a braços"7. Em geral, as declarações daqueles que presenciaram este momento apresentam vários indicativos de que a situação anárquica em que se encontravam as tropas brasileiras por volta de 1831 foi um dos principais problemas com os quais a Regência Trina Definitiva se debateu no momento de sua instalação.

Foi possivelmente em função disso, que os membros do governo regencial optaram pela drástica redução dos efetivos militares que se observa ao longo do período de 1832 a 1837, quando estes números caíram de 12.200 homens em 1831 - contando-se apenas os praças de prét - para 6.320 homens em 1837 - número relativo tanto aos praças como aos oficiais do Exército $^{8}$. Apesar da proposta de fixação de forças para o ano financeiro de 1833 e 1834 também estar repleta de menções à "anarquia" das tropas como principal causa para a redução dos efetivos militares, não é possivel afirmar que exista um consenso em relação a este ponto dentro da historiografia.

Para Edmundo Campos Coelho, por exemplo, o comportamento da elite brasileira em relação ao Exército ao longo do Período Imperial poderia ser definido como uma "política de erradicação" alimentada por constantes atitudes hostis em relação à existência de uma Força Armada permanente 
COELHO, Edmundo Campos. Em busca de identidade: o Exército e a Política na sociedade brasileira. Rio de Janeiro: Forense-Universitária, 1976, p. 39.

10

A Guarda Nacional foi uma milícia civil criada no periodo regencial, para substituir as antigas milícias e ordenanças existentes no periodo colonial. Sobre o tema, ver: CASTRO, Jeanne Berrance de. A milícia cidadã: a Guarda Nacional de 1831 a 1850. São Paulo: Editora Nacional, 1977.

\section{1}

0 antagonismo existente entre as exigências militares e o sistema escravista também é tema explorado por Hendrik Kraay. Analisando o caso baiano, o autor demonstra que o recrutamento de alguns escravos por parte das tropas patrióticas durante a guerra de Independência na Bahia acabou gerando abalos significativos para o regime escravista naquela região. Ver: KRAAY, Hendrik. "Em outra coisa não falavam os pardos, cabras e crioulos": o "recrutamento" de escravos na guerra da Independência da Bahia. Revista Brasileira de História. Vol. 22, nº 43 São Paulo, 2002.

\section{2}

COSTA, Wilma Peres. A Espada de Damôcles: o Exército, a Guerra do Paraguai e a Crise do Império. São Paulo: HUCITEC, UNICAMP, 1996, p. 27-68.

13

IZECKSOHN, Op. Cit, p. 62-63. e profissional no pais. Segundo o autor, esta hostilidade provinha ainda do periodo colonial, pois as tropas portuguesas eram usadas para reprimir grupos ligados a atividades de fraude, fisco, contrabando, e também pela violência com que eram feitos os recrutamentos sobre a massa geral da população. Ainda nesta direção, a manutenção da monarquia sob a égide de um príncipe oriundo de uma "dinastia de soldados", durante o processo da Independência, teria colaborado para o acirramento desse espírito antimilitar, uma vez que este parecia sempre disposto a usar as tropas para conter as autonomias regionais e os movimentos de contestação ao regime. Ainda de acordo com o autor, a abdicação de D. Pedro I, "na crista de uma rebelião militar, forneceu à classe política a oportunidade de virtualmente licenciar o Exército, sob o pretexto da indisciplina militar que ela própria fomentara, e criar a Guarda Nacional"9. Como veremos mais adiante, no entanto, não há razões para se acreditar que a elite política brasileira se opusesse à existência de um Exército profissional e permanente, nem tampouco que pretendesse substitui-lo pela Guarda Nacional ${ }^{10}$, assim como sugere Coelho.

Outros autores, como Wilma Peres Costa e Vitor Izecksohn, além de também reiterar, embora em menor grau, a idéia de que a elite política alimentava um certo receio em relação ao elemento militar, sugerem que as raizes do processo de desmobilização das tropas se encontram justamente na forma como se deu o processo de formação do Estado Nacional brasileiro, ou seja, sem uma guerra de Independência muito longa, nem rupturas com o aparato militar colonial, evitando, assim, um processo revolucionário que pudesse ocasionar a desintegração do sistema escravista, tal como havia ocorrido na América Espanhola11. Para Costa, ao mesmo tempo em que a escravidão havia unido as elites em torno do governo monárquico, também impôs sérios limites ao Estado nascente, dentre os quais estava a impossibilidade de exercer um "monopólio da violência legítima". Com efeito, a escravidão diminuía a população recrutável, e também impossibilitava o desarmamento dos agentes privados, tendo em vista o perigo de sublevações escravas ${ }^{12}$. Além disso, conforme explica Izecksohn, não havia mesmo garantias de que

a monopolização dos meios de coerção favorecia o governo. Assim, um fortalecimento do setor militar não fazia parte dos planos imediatos da elite politica, que manifestava clara preferência pela solução proporcionada pela Guarda Nacional. Esta alternativa (...) dispensava o governo das preocupações comuns aos países do Prata com a ameaça de interferência militar na vida política do país ${ }^{13}$.

Portanto, para estes autores, a desmobilização das tropas de terra no período regencial se deu tanto pela "incapacidade extrativa" do Estado brasileiro, como também pela desconfiança da elite política em relação ao elemento militar, o que teria redundado em marginalização do Exército dentro do sistema político imperial e, conseqüentemente, em fomento de um ressentimento entre os membros do seu núcleo profissional em relação ao governo monárquico. Sem desconsiderar os argumentos expostos por estes autores, este artigo tem como objetivo propor uma nova leitura para a questão da desmobilização das tropas e seus impactos sobre o relacionamento entre os oficiais do Exército e a elite política brasileira. A nossa intenção é demonstrar que a diminuição dos efetivos militares foi feita com o apoio e a iniciativa de um grupo de oficiais do próprio Exército - como 
De acordo com Marco Morel, o Rio de Janeiro dos anos 1830 foi palco de uma disputa entre três grupos políticos: o dos Restauradores ou Caramurus, que defendiam as permanências do absolutismo, o retorno de D. Pedro I, e até mesmo a recolonização portuguesa, o dos Liberais Moderados, que almejavam mudanças dentro da ordem constitucional e, finalmente, o dos Exaltados, que apontavam para mudanças bem mais profundas, como o federalismo, a ampliação das liberdades, etc. Embora liberais moderados e exaltados tivessem se unido na oposição ao reinado de Pedro I, durante a regência este quadro sofreu algumas mudanças. Os moderados consolidaram-se no poder central e tornaram-se os defensores da ordem; pelo seu radicalismo, os exaltados foram sumariamente afastados. MOREL, Marco. Cipriano Barata na Sentinela da Liberdade. Salvador: Academia de Letras da Bahia; Assembléia Legislativa do Estado da Bahia, 2001, pp: 246-269.

\section{5}

LEÃO, Honório Hermeto Carneiro. Relatório da Repartição dos Negócios da Justiça, apresentado à Assembléia Geral Legislativa na sessão ordinária de 1832 pelo respectivo Ministro e Secretário de Estado. Rio de Janeiro, Tipografia Nacional, 1832, pp. 12-14.

\section{6}

Natural do Rio Grande do Sul, Antero José Ferreira de Brito nasceu em 11 de janeiro de 1787. Alistou-se em 1808 nas antigas milicias do Sul e participou das campanhas da Cisplatina em 1811-1812. Lutou nas guerras de Independência na Bahia e, posteriormente, em Pernambuco, por ocasião da Confederação do Equador, 1824. Exerceu importantes cargos, e foi agraciado com o título Barão de Tramandaí a 14 de março de 1854. Faleceu a 5 de fevereiro de 1856.Em: LOPES, T. e TORRES, G. Op. Cit, pp. 57-58.

17

BRIT0, Antero José Ferreira de. Relatório da Repartição dos Negócios da Guerra, apresentado à Assembléia Geral Legislativa na sessão ordinária de 1834 pelo respectivo Ministro e Secretário de Estado. Rio de Janeiro: Tipografia Nacional, 1834, p. 1.

\section{8}

Como observa José Murilo de Carvalho, a rigor, não haviam partidos políticos no Brasil até 1836, mas sim organizações políticas ou pára-políticas, que haviam saido da clandestinidade após a Independência. Em 1836, restauradores e alguns monarquistas liberais uniram-se para criar o Partido Conservador, em oposição aos demais monarquistas liberais, que deram origem ao Partido Liberal. Estes grupos se distinguiam sobretudo por sua concepção acerca do tipo de Estado Liberal que deveria ser implantado no país, problema que veio à tona com a Abdicação de Pedro I. Os conservadores propugnavam o desenvolvimento de uma monarquia forte e centralizada, a exemplo da francesa, e os liberais pretendiam instalar uma monarquia federalista, aos moldes ingleses e norte-americanos. Ver: CARVALHO, José Murilo de. A construção da ordem e Teatro de sombras. Rio de Janeiro: Editora UFRJ/Relume Dumará, 2003, pp. 201-208. eram os casos, por exemplo, de Manoel da Fonseca Lima e Silva, José Felix Pereira Pinto Borges e de Antero José Ferreira dos Santos - todos preocupados com o "estado de anarquia" em que se encontravam as tropas de terra desde, pelo menos, o período da abdicação de D. Pedro I. Estes oficiais acreditavam que um núcleo militar pequeno, mas bem organizado, seria mais suscetivel ao desenvolvimento de um processo de nacionalização e profissionalização da instituição militar brasileira, interesses que convergiam com o dos liberais moderados, grupo que se consolidou no poder logo no início do período regencial14.

Ainda nesta direção, observa-se que este projeto esteve articulado à criação da Guarda Nacional e ao surgimento de novas concepções sobre a questão da segurança, aspectos que abriram caminho para a redução das tropas de terra naquele período. Com a criação da Guarda Nacional, esperava-se que as tropas profissionais pudessem se concentrar exclusivamente na manutenção da defesa externa do país, ao passo que as atividades de policiamento, e a manutenção da paz interna, seriam feitas pela milícia cidadã. Entretanto, esta crença não se sustentou por muito tempo, e já em 1832 podemos encontrar algumas críticas em relação à Guarda Nacional, como é o caso desta, proferida pelo então ministro da Justiça, Honório Hermeto Carneiro Leão:

Vós sabeis que este serviço [de Guardas Nacionais], que ao principio era feito com zelo, e patriotismo, deixou de o ser desde que o receio da anarquia desapareceu (...) As penas de disciplina aplicadas às Guardas Nacionais de França não são eficazes neste Império: ali existe um numeroso Exército, uma força policial suficiente; aqui, pode-se dizer que não existe Exército, e que a força policial é quase nula; portanto o serviço que ali se exige da Guarda Nacional, não tem comparação com o forçado e contínuo que atualmente se está exigindo (...) Além disso, muitos Guardas Nacionais do Império, acostumados ao regime austero das Milícias, zombam inteiramente das penas (...) alguns ocultam-se em casa para não serem presos, e os Juizes de Paz (...) recusam passar Mandatos para se Ihes entrar em casa15.

Ao mesmo tempo em que a Guarda Nacional havia se mostrado insuficiente e despreparada para a realização de atividades de policiamento, que era a queixa principal do referido ministro da Justiça, também se mostrou absolutamente incapaz de manter a ordem e a unidade nacional na medida em que várias rebeliões começavam a despontar em diversas partes do Império. Apesar disso, os ministros da guerra ligados ao governo regencial mantiveram o processo de desmobilização das tropas, julgando que bastava completar os limitados contingentes fixados em 1833, e organizar o Exército; isso era o que propunha, por exemplo, o ministro da guerra Brigadeiro Antero José Ferreira de Brito ${ }^{16}$, em 1834, declarava que embora "nem no Exterior se observa que esteja desvanecido o projeto de uma Restauração [do Governo de D. Pedro I], nem no Interior que os seus sectários hajam perdido inteiramente as esperanças (...) entende o mesmo Governo não ser por ora necessário outro aumento na dita Força [de 1a Linha]"17.

Com a abdicação de Feijó em 1837, e a ascensão do recém-fundado Partido Conservador ${ }^{18}$ ao poder, inicia-se o período que ficou conhecido como regresso conservador. Além da reforma das leis descentralizadoras, os efetivos militares novamente voltaram a crescer, em detrimento do projeto alimentado por políticos e oficiais moderados até aquele momento. Entre os 
19

BARROS, Sebastião do Rego. Proposta da Repartição dos Negócios da Guerra, apresentada à Assembléia Geral Legislativa na Sessão Ordinária de 1838 pelo respectivo Ministro e Secretário de Estado. Rio de Janeiro: Tipografia Nacional: 1838, p. 1 .
20

Os defensores da tese da instrumentalidade acreditam que os militares atuam politicamente com base em interesses das classes sociais, e em especial, dos setores médios da sociedade; esse é o caso, por exemplo, de: SAES, Décio, A formação do Estado Burguês no Brasil (1888-1891). Rio de Janeiro: Paz e Terra, 1985. A defesa da perspectiva organizacional, por sua vez, aparece em: CARVALHO, José Murilo de, "As Forças Armadas na Primeira República: o poder desestabilizador". In: FAUSTO, Boris (Org.) História Geral da Civilização Brasileira. Tomo III, Vol II, São Paulo: Difel, 1977. políticos e oficiais conservadores o processo de desmobilização seria muito mal visto, como bem o denota a crítica feita por Sebastião do Rego Barros, ministro da guerra em 1838:

Acresce ainda que, havendo-se criado algumas companhias Provisórias, que não fazem parte do Exército, e tendo-se chamado em outras a Guarda Nacional para o serviço ordinário e extraordinário (...) para suprir a falta de tropa de $1^{a}$ Linha, em último resultado sucede que sem termos em vigor um Exército regular, temos contudo, senão maiores, todos os gravames que indispensavelmente o acompanham; resultando dai um tal estado de coisas, que nem todas as Provincias se acham suficientemente guarnecidas, nem tampouco a Força existente apresenta, nem pode apresentar, aquela unidade que Ihe avigora a ação, e aquela disciplina e organização que the é mister ${ }^{19}$.

Não cabe a nós julgar retrospectivamente qual das duas vertentes do oficialato deste período alimentava o "melhor" projeto para as Forças Armadas. Apenas pareceu-nos importante ressaltar que havia fortes clivagens no interior da alta cúpula militar, e que tais clivagens contribuíram para que seus membros encarassem o processo de desmobilização de uma forma bastante diferenciada. Aparentemente, a perspectiva alimentada pelos oficiais ligados aos moderados durante o período regencial não foi ainda suficientemente explorada pela historiografia, e por isso mesmo, talvez demande aqui maior atenção da nossa parte. Nossa intenção é demonstrar que, para tais oficiais, a desmobilização de parte das tropas em 1831 constituiu um esforço de racionalização da estrutura militar herdada do Antigo Regime português, e não significou, pelo menos não até aquele momento, motivo de discórdia entre os oficiais e o governo brasileiro.

Afinal, como se verá adiante, é preciso ressaltar que o governo regencial tentava dirigir o Império de maneira diferenciada em relação ao $1^{\circ}$ Reinado - que foi marcado por grande centralização do ponto de vista político, e pelo senhorialismo do ponto de vista militar, notadamente no que dizia respeito à contratação de mercenários, e à concessão de altas patentes especialmente aos oficiais portugueses. Impunha-se à nova ordem política estabelecida no periodo regencial, a tarefa de edificar o Estado brasileiro sobre bases novas, "constitucionais" e "nacionais"; é possivel acreditar que também a oficialidade militar deste período sentiu-se encarregada de uma missão semelhante, pois o que se observa ao longo dos cinqüenta anos que se seguem é justamente esta tentativa, por parte dos oficiais - e independentemente de filiação partidária - de promover a nacionalização e a profissionalização das Forças Armadas. Cabe aqui ressaltar que a análise deste processo nos fornece muitos indícios de que a atuação pública destes oficiais deve ser compreendida como fruto dos seus interesses organizacionais 20 , e não como meros reflexos das disposições de classe, ao contrário do que sugerem os defensores da "perspectiva instrumental" das Forças Armadas.

\section{Exército brasileiro em 1831}

Durante o periodo da Abdicação, as tropas brasileiras apresentavam ainda nítidas características de um exército tipicamente senhorial, como por exemplo, o fato da sua oficialidade ser majoritariamente recrutada entre os membros da elite local, recebendo o título de cadete ainda na infância, em conformidade com as práticas do Antigo Regime Português. De acordo com Adriana Barreto de Souza, "de ascendência nobre ou não, essa geração (...) 
21

SOUZA, Adriana Barreto de. "A serviço de sua Majestade: a tradição militar portuguesa na composição do generalato brasileiro (183750)". In: CASTRO, IZECKSOHN, KRAAY (Orgs) Nova História Militar Brasileira. Rio de Janeiro: Editora FGV, 2004, p. 167.

22

RODRIGUES, Fabiana Mehl Sylvestre. Dos "tarimbeiros" aos "bacharéis de farda": modernização, corporativismo e conflito no Brasil imperial (1860-1880). Monografia de conclusão de curso. UFPR: 2004.

23

COSTA, op. Cit, pp. 42-43.

Decisões de Governo: Ministério da Guerra, 10 de Julho de 1822. Coleção das Leis do Império do Brasil, 1822. Rio de Janeiro: Imprensa Nacional, 1889, pp. 56-57.

25

HOLANDA, Sergio Buarque de. Do Império a República. In: HOLANDA (Org). História Geral da Civilização Brasileira. Rio de Janeiro: DIFEL, 1997, p. 330 era integrada por oficiais completamente subordinados à Coroa e dependentes de sua generosidade"21. Dessa forma, observa-se que ao receberem o título de cadete, eles eram dispensados de ingressar nos postos subalternos, passando por rápidas promoções, que muitas vezes eram acompanhadas por outros títulos honoríficos, como o de marquês ou barão. Alguns historiadores têm interpretado a origem social desta primeira geração do Exército nacional como determinante de um comportamento político reacionário, marcado por uma vinculação mínima com a instituição militar, e geralmente se considera que estes oficiais agissem mais como "homens de partido" do que como militares. De fato, a ascendência aristocrática, a fidelidade à monarquia parlamentar e seus engajamentos partidários são aspectos notórios dentro deste grupo. Mas acreditamos que eles não eram, necessariamente, contrários ao engajamento institucional, não só porque muitos deles pertencessem a famílias de grande tradição militar - como é o caso dos Lima e Silva, por exemplo - mas também porque quando acompanhamos a trajetória política destes oficiais, especialmente nos ministérios da guerra, é possivel observar que eles estavam freqüentemente lutando por uma melhoria das condições das Forças Armadas no pais22.

Um outro aspecto que se observa neste período, é que as fileiras de soldados eram constantemente preenchidas por grupos de mercenários, outra herança portuguesa que foi reiterada pela política militar de D. Pedro I. Como observa Wilma Peres Costa, a adoção de mercenários foi uma das principais fontes da impopularidade do príncipe, visto que, além de duvidar-se da eficiência dos estrangeiros engajados - usados, por exemplo, na campanha em que o Brasil havia perdido a Província da Cisplatina também ainda era muito presente "o terror vivido pela população do Rio de Janeiro quando as tropas estrangeiras se amotinaram". Refere-se a autora ao fato de que em 10 de junho de 1828, "uma seção sádica de castigos corporais, em que a ordem de 25 chibatadas foi aumentada para 125, deu início ao motim que ensangüentou a cidade por dois dias"23.

Assim como ocorria com os mercenários, os soldados recrutados entre os brasileiros também não desfrutavam de nenhum prestígio social, sendo freqüentemente vistos como pessoas pouco idôneas e perigosas à tranqüilidade pública. Também isto pode ser considerado, de certa forma, uma herança da estrutura militar portuguesa, tendo em vista que foi no periodo da Regência de Pedro I - 1822 - que se marcaram as instruções de recrutamento que, depois de consagradas pelo hábito, estiveram em vigor durante praticamente todo o período Imperial. 0 autor destas instruções, Luiz Pereira Nóbrega de Souza Coutinho, alertava as autoridades responsáveis que era preciso fazer "mais ativo recrutamento", sem, no entanto, ocasionar nenhum prejuizo para as "Artes, Navegação, Comércio e Agricultura, fontes da prosperidade pública", de modo que este deveria compreender todos os homens "brancos solteiros, e ainda pardos libertos de idade de 18 a 35 anos", que não tivessem nenhuma "pública ocupação, ou legal indústria, viveiros de criminosa ociosidade"24. Diante da imensa rede de isenções estabelecida por estas instruções, e a margem que este texto dava para interpretações arbitrárias, como por exemplo, a concessão de isenções somente para aqueles que apresentassem um "bom comportamento", o sistema de recrutamento abarcava apenas aqueles indivíduos indesejados nas Províncias, em especial, os "desprotegidos e os desocupados, que se viam compelidos, geralmente por exigências políticas, a ingressar nas fileiras militares" 25. 
MENDES, Fabio Faria. "Encargos, privilégios e direitos: o recrutamento militar no Brasil nos séculos XVIII e XIX". In: CASTRO, IZECKSOHN, KRAAY (Orgs) Op. Cit, pp. 111-137.

27

LOPES, TORRES, Op. Cit, p. 56.

28

SILVA, Manoel da Fonseca Lima e. Proposta para o ano de $1831 \ldots$ pp. 1-2.

29

Lei de 18 de Agosto de 1831. Coleção das Leis do Império do Brasil, 1831. Rio de Janeiro: Tipografia Nacional, 1875, p. 62.

30

Idem, p. 49.
Tendo em vista a desconfiança que se tinha em relação ao uso de mercenários, bem como às dificuldades de recrutamento inerentes a complexa rede de isenções e privilégios herdada do Antigo Regime português ${ }^{26}$, fica bastante evidente que seria muito difícil para o governo regencial, conseguir alcançar o efetivo de 14.000 homens - compreendendo praças e oficiais - que havia sido proposto pelo General José Manoel de Morais, primeiro ministro da guerra do período regencial27. Portanto, ao substituí-lo na pasta da guerra, em julho de 1831, é possível crer que o coronel Manoel da Fonseca Lima e Silva tivesse uma dupla missão: superar o problema da insubordinação e da indisciplina das tropas instaladas na Corte e nas Províncias, e completar os quadros fixados para as tropas de linha, sem que o sistema arbitrário e violento do recrutamento, ou mesmo o contrato de mercenários, significassem um risco à estabilidade do país, já suficientemente ameaçada pelos eventos anteriores. Analisando por este ângulo, pareceu-nos bastante evidente que a desmobilização parcial das tropas pode ter sido uma das poucas soluções encontradas, não só para a resolução destes problemas de ordem mais imediata, como também para se iniciar um processo de profissionalização e nacionalização do Exército. Como declarava o próprio Coronel Manoel da Fonseca Lima e Silva, "cumpre não perder de vista que mais vale pequena Força bem organizada, fardada, e mantida, do que triplicado número mesquinhamente pago, que será de enorme peso à Nação, de grande escândalo à moral, e finalmente, sempre disposto a concorrer para a perturbação da tranqüilidade pública"28.

\section{Aspirações dos oficiais moderados}

0 processo de desmobilização do Exército ocorreu paralelamente - e esteve intimamente relacionado - com a fundação da Guarda Nacional, milícia cidadã, subordinada ao Ministério da Justiça e autoridades civis, criada a partir de modelo franco-americano, e que tinha como finalidade substituir os corpos de milícias, guardas municipais e ordenanças existentes desde 0 período colonial. 0 serviço da Guarda Nacional era obrigatório a todos os cidadãos eleitores em idade de 21 a 60 anos - com algumas ressalvas para aqueles que exercessem profissões consideradas incompativeis com esta atividade. Além de não perceberem remuneração, os guardas-nacionais também eram responsáveis pela manutenção do seu fardamento e armamento. Provavelmente em função disso, pressupunha-se que em "todos os casos em que as Guardas Nacionais concorrerem com tropas de linha", tomariam "o lugar mais distinto"29. É muito provável que estas milícias realmente tenham sido criadas com o objetivo de oferecer um contraponto para o elemento militar, caso este ameaçasse subverter a hegemonia politica civil. Em seu texto de criação, por exemplo, vemos que competia à milícia cidadã "defender a Constituição, a Liberdade, Independência, e Integridade do Império" e "restabelecer a ordem e a tranqüilidade pública"30, ou seja, ela deveria evitar tudo o que a elite civil considerava temível em face de exemplos ocorridos na América espanhola:

Desde que há tropas, há generais, chefes e superiores acostumados a mandar e ser obedecidos; com muita dificuldade se familiarizam com a marcha demorada da lei, que tantas garantias oferecem aos cidadãos contra aqueles que só querem ser obedecidos. Tendo por hábito e por afeição a satisfazer seus caprichos (...) qualquer pretexto basta para precipitá-los na carreira revolucionária. Sem irmos longe, temos a escola dos 
31

CALDEIRA Op. Cit. p. 137

32

(Grifo nosso) Lei de 18 de Agosto de 1831. Coleção das Leis do Império do Brasil, 1831... p. 49.

33

SILVA, Manoel da Fonseca Lima e. Proposta para o ano de 1831... pp. 1-2. nossos vizinhos. As Américas espanholas retalharam-se em tantas repúblicas quantas quiseram seus generais. A Colômbia e o México, que apresentavam melhor aspecto, têm-se subdividido, e ainda hoje são a presa dos generais ambiciosos, que se disputam a preferência em dominá-las ${ }^{31}$.

Acreditamos que apesar de a elite política alimentar um certo receio em relação ao elemento militar, a maioria não se opunha - como o fez abertamente Feijó - à existência de uma força militar permanente e profissional no pais. Vale lembrar que apesar da redução dos quadros militares, as tropas de linha continuaram recebendo atenções e estímulos, mesmo durante a regência de Feijó, um antimilitarista declarado. Assim, não é possivel afirmar que a Guarda Nacional tenha sido criada com o objetivo de substituir as tropas profissionais, mas, pelo contrário, entre as suas finalidades, observa-se que ela deveria "auxiliar o Exército de Linha na defesa das fronteiras e costas" 32 .

Acreditamos que a criação da Guarda Nacional pode ser vista também como um indício das transformações ocorridas na concepção da elite política brasileira com relação à questão da segurança nacional. Com a consolidação dos moderados no poder, começava a surgir a idéia de que o Exército servia para proteger a Nação contra ataques externos e defesa da soberania, e não para realizar atividades de policiamento, que não cabiam ao Ministério da Guerra, mas sim ao Ministério da Justiça e às autoridades provinciais e municipais. Dessa forma, observa-se que na medida em que a elite política começava a diferenciar a violência feita contra a sociedade como competência da atividade policial - da violência feita contra o Estado - competência das tropas profissionais - abria-se o caminho para a redução dos efetivos do Exército:

Em tempos ordinários, e quando a paz residir em todos os ângulos do Império, reconhece o Governo a desnecessidade de um Exército numeroso, bastando a conservação dos Corpos, que sirvam como de Escola normal de subordinação e rigorosa disciplina militar; porque as Guardas Nacionais nas Provincias onde estiverem organizadas (...) prestarão grande auxilio, e coadjuvarão com energia e verdadeiro interesse na defesa do Estado. Fundado nestas razões julga o Governo que o quadro do Exército Nacional, organizado segundo o decreto de 4 de maio de 1831 (...) pode ser desde já diminuido33.

Os aspectos que apontamos até o momento podem esclarecer as razões pelas quais a elite política brasileira encarava com otimismo o processo de desmobilização das tropas e aplicação da Guarda Nacional na defesa da manutenção da segurança interna, mas dificilmente explicam as expectativas de alguns oficiais que, conforme vimos anteriormente, equacionavam a diminuição dos efetivos a um avanço no processo de profissionalização e nacionalização das tropas de linha. Para se compreender melhor este aspecto, é importante lembrar que, ao assumir a pasta da Guerra, em julho de 1831, o Coronel Manoel da Fonseca Lima e Silva, tinha em suas mãos um Exército incompleto, indisciplinado e rebelde, provavelmente não sem motivos, tendo em vista que ele mesmo reconhecia que as tropas eram "mesquinhamente pagas", e que havia dificuldades em fardá-las e mantêlas. Mas conforme se observa na sua proposta, um dos maiores problemas era justamente o de alcançar os efetivos fixados pelo Ministério anterior, principalmente em decorrência do "estado de defecção a que chegou o 
34

SILVA, Manoel da Fonseca Lima e. Proposta para 0 ano de $1831 \ldots$ p. 1.

35

SILVA, Manoel da Fonseca Lima e. Proposta para o ano de $1831 \ldots$, p. 1.

36

SILVA, Manoel da Fonseca Lima e. Relatório do ano de $1831 \ldots$, p. 5.

37

Idem, p. 6

38

Idem, p. 8.
Exército" e do "espírito vertiginoso que se apoderou dele". Dizia o Ministro que diante da sublevação das tropas - ocorridas nos dias anteriores à sua indicação para a pasta da Guerra - não poderia "sem ser com razão taxado de temerário e imprudente, solicitar atos Legislativos, que levem a força do Exército ao seu estado completo decretado". Ademais, aduzia o ministro que com uma "população exausta", com a ausência de "uma Ordenança geral análoga aos costumes e idéias da Nação", e de "Leis da primeira necessidade a que está ligada à disciplina, que só, e unicamente, pode manter a ordem" e retirar do "Exército as faculdades de ser nocivo a Nação", era aconselhável uma vigorosa "oposição contra a adoção de semelhante proposta, ao menos enquanto não for promulgada uma Lei que regule o modo de proceder no Recrutamento"34.

Neste sentido, observa-se que, para os oficiais envolvidos no processo de desmobilização das tropas de terra de 1831, era preferivel licenciar parte do Exército do que recorrer ao violento sistema de recrutamento herdado do período anterior, que não só alarmava as populações, alimentando hostilidades em relação à carreira militar, como também não era capaz de fornecer àquela corporação os contingentes fixados por lei. Dessa forma, eles acreditavam que um novo sistema de recrutamento, aliado à melhoria dos soldos e das condições em que o soldado servia, concorreriam para que "cidadãos probos, proprietários, e mais pessoas interessadas na segurança do Pais, em vez de corar por verem seus filhos incorporados nas fileiras do Exército" se enchessem "de orgulho por se haverem eles consagrado à defesa da Pátria"35. No entanto, apesar da insistência com que muitos Ministros da Guerra abordaram a questão do recrutamento, observa-se que este se manteve intocado durante praticamente todo o periodo imperial.

\section{A desmobilização das tropas e seus limites}

Como procuramos ressaltar, o processo de desmobilização das tropas de terra não se limitou à drástica redução dos efetivos militares, mas também significou uma tentativa, por parte dos oficiais e políticos moderados de promover a racionalização da estrutura militar herdada do Antigo Regime Português. Dessa forma vemos que o Relatório do Ministério da Guerra produzido pelo Coronel Manoel da Fonseca Lima e Silva entre anos 1831 e 1832, está repleto de críticas à administração anterior que, geralmente por patronato, havia povoado o Estado Maior do Exército com um número excessivo de oficiais que nem sequer tinham as preliminares e "circunstâncias de rigorosamente serem considerados como tais", e que não eram empregados em nenhuma Comissão, "limitando-se a viver em pleno ócio, vencendo o soldo, sem haverem prestado algum serviço, ao tempo que outros não tinham momento para descansar"36. Da mesma forma, criticava a "monstruosidade" feita em relação aos oficiais empregados no Comando das Fortalezas, que percebiam gratificações menores do que outros oficiais da mesma classe, resultando dai que "a nomeação para um comando" destes era "na realidade uma espécie de castigo"37, que deixava estes mesmos oficiais em condições inferiores em relação aos demais. Ainda conforme o ministro, também a anarquia em que se encontravam as tropas podia ser atribuída a administração anterior, que havia criado um "errôneo sistema de recrutar", "próprio somente para expurgar as Províncias dos homens mais abomináveis por seus vícios, índole turbulenta, e horrorosos crimes, gente sempre perigosa à tranqüilidade pública", que haviam transformado o Exército em um "depósito de facinorosos obcecados"38. 
SILVA, Manoel da Fonseca Lima e. Proposta para 0 ano de $1831 \ldots$, p. 2.

41

Sebastião do Rego Barros era natural de Pernambuco. Nascido em 18 de agosto de 1803 bacharelou-se em ciências matemáticas pela Universidade de Gottingen, na Alemanha e, de volta ao Brasil, entrou para o corpo de Engenheiros do Exército no qual chegou ao posto de tenente-coronel. Faleceu a 7 de março de 1863. Ver: LOPES, T. e TORRES, G. Op. Cit, p. 61.
Diante de tudo isso, em seu Ministério procurou-se realinhar o quadro de oficiais do Exército conforme as necessidades do serviço militar, e prosseguiu-se "no arbitrio de mandar regressar às suas Províncias, e restituir às suas famílias, todas aquelas Praças dos Corpos, que por anos estiveram delas ausentes"39. Ainda nesta direção, várias pessoas que trabalhavam nos estabelecimentos a cargo do Ministério da Guerra - que começavam a ser reformados - foram desempregadas, pois eram consideradas completamente supérfluas na Repartição da Guerra. 0 processo de desmobilização não atingiu os corpos de cavalaria, artilharia e de engenharia, pois um pessoal suficientemente instruído e treinado no exercício destas armas não seria algo fácil de se obter em ocasiões de guerra. Aparentemente, o próprio Coronel Manoel da Fonseca Lima e Silva percebia que o sucesso da desmobilização das tropas dependia de alguns aspectos importantes, como por exemplo, a já mencionada reforma no sistema de recrutamento. Além disso, é possivel perceber que estes oficiais acreditavam que o país iria passar por um período de relativa tranqüilidade, e que não havia motivos para se esperar qualquer agressão dos Estados limitrofes do Império; ao mesmo tempo, alimentavam a forte convicção de que, diante da eminência de uma guerra, tanto a Guarda Nacional como muitos outros cidadãos voluntariamente preencheriam as fileiras do Exército:

Nas crises extraordinárias quando inimigos externos nos venham perturbar em nosso território, é obvio que a defesa do Estado se não pode absolutamente fazer com o Exército assim reduzido, não obstante a cooperação das Guardas Nacionais: então o Brasil será salvo pelos meios também extraordinários que a Assembléia Geral Legislativa subministrar no Governo; os Corpos do Exército servirão de núcleo à Organização de novos corpos temporários, e o Patriotismo já tão pronunciado e desenvolvido em todas as Classes dos Cidadãos Brasileiros, os levará com espontânea prontidão a engrossar as fileiras do Exército no lugar onde mais eminente perigo ameaçar a Pátria que idolatram, e pela qual não hesitarão em fazer os maiores sacrificios ${ }^{40}$.

Embora a desmobilização das tropas tenha sido uma alternativa razoável para que os políticos e oficiais moderados promovessem uma reorganização do Exército herdado do período anterior - a partir do expurgo dos elementos indesejáveis e da supressão dos empregados supérfluos oriundos do patronato vigente no Primeiro Reinado - ela não tardou a encontrar os seus limites, principalmente porque havia sido fundamentada em uma confiança exagerada em relação à Guarda Nacional, bem como à coesão e ao patriotismo do povo brasileiro, o qual ainda dava os seus primeiros passos como "nação". Desta forma, observa-se que durante a década de 1830 inúmeras rebeliões com viés separista começaram a assolar o país, demarcando não somente a incapacidade da Guarda Nacional em manter a ordem interna, mas também o fato de que ela era pouco digna de confiança, tendo em vista que muitos dos seus corpos participaram ativamente, por exemplo, da Revolução Farroupilha (1835-1845). Em 1837, o Regente Feijó foi substituido pelo conservador Pedro de Araújo Lima, que chamou o Tenente-Coronel Sebastião do Rego Barros ${ }^{41}$ para assumir o Ministério da Guerra. Uma das primeiras medidas daquele gabinete foi promulgar um decreto que trazia muitos oficiais de volta à ativa, restabelecendo, portanto, as tropas de terra: 
42

BARROS, Sebastião do Rego. Proposta da Repartição dos Negócios da Guerra..., p. 1.

43

SCHULZ, Op. Cit, p. 26

44

Os contingentes efetivamente passaram por um aumento considerável: quando os conservadores assumiram a Regência, em 1837-38, estes números aumentaram para $8.200 \mathrm{em}$ tempo de paz, e 12.000 homens em tempo de guerra (contando-se praças e oficiais). No ano seguinte, 12.000 homens em tempo de paz e 15.000 em tempo de guerra (apenas praças). Até 1849, se manteve o número de 15.000 homens em tempo de paz, sendo que os contingentes extraordinários passaram de 18.000 para 20.000. Nos anos seguintes ainda se observa uma ascensão nestes números, que só cairam novamente em 1862 e 1863, época de predomínio político dos liberais, na qual se estabeleceu o número de 14.000 homens em tempo de paz. Com a Guerra do Paraguai os efetivos extraordinários chegam ao número de 60.000 , mantido entre os anos 1865, 1866, 1867, 1868 e 1869. Idem, p. 216.
Pelo que respeita ao limite das Forças propostas, cumpre-me observar-vos que suposto o Governo esteja na convicção de que em breve cessarão os efeitos da vertigem revolucionária, que tanto tem empecido o progresso da nossa civilização e prosperidade, e tenha bem assim a esperança de ver em pouco tempo ligadas por um vinculo indissolúvel todas as partes do Império, única condição de felicidade (...) todavia o ainda convulsivo de algumas localidades, e as circunstâncias especiais de outras, reclamam altamente a presença de Forças mais ou menos consideráveis (...) indispensável se torna que se proporcionem os precisos meios de força, seja para manter a ordem interna do pais, seja para repelir qualquer invasão estrangeira, e fazer respeitar a dignidade e a honra Naciona ${ }^{42}$.

Em 1841, o Exército revitalizado e comandado pelo futuro Duque de Caxias, derrotou a Sabinada na Bahia (1837/38), a Balaiada no Maranhão (1838/1839) e, na seqüência, teve participação ativa na sufocação das revoltas liberais em São Paulo e Minas Gerais (1842), na Revolução Farroupilha no Rio Grande do Sul (1845) e, finalmente, na Revolta da Praieira em Pernambuco (1849) ${ }^{43}$. Depois de alcançada a paz interna, o Império brasileiro ainda iria promover uma política relativamente ofensiva na Bacia Platina, com a campanha contra Oribe e Rosas (1851-1852) e, posteriormente com a intervenção no Uruguai (1864) que redundou na Guerra da Tríplice Aliança.

Todos estes fatores contribuíram para que os efetivos militares fossem continuamente ampliados até o final dos anos $1870^{44}$, determinando, pelo menos até este periodo, um arrefecimento no projeto de organização de um "núcleo militar pequeno e bem organizado". Embora a desmobilização das tropas tenha sido sempre muito criticada pelos conservadores e também vista, futuramente, por muitos membros das novas gerações de oficiais como uma forma de se marginalizar o Exército no cenário político nacional, a análise do seu processo de criação e consecução, após 1831, indica que, naquele periodo, alguns militares a encaravam com um certo otimismo, pois em função dos escassos recursos existentes, e de outras razões já mencionadas ao longo deste artigo, considerava-se preferivel manter um Exército pequeno, que seria mais susceptível às reformas que se faziam necessárias naquele momento. No entanto, cabe aqui ressaltar que ao longo do Segundo Reinado os políticos liberais não foram capazes de operar as mudanças que o Exército necessitava para se profissionalizar e, por isso mesmo, foram perdendo prestígio junto aos oficiais que encontraram dentro do Partido Conservador melhores aliados para a modernização da sua instituição.

Neste sentido, é importante ressaltar que a análise do contexto em que se deu a elaboração e consecução do processo de desmobilização das tropas de terra, sobretudo a partir das proposições feitas pelos seus principais agentes, revela que a alta cúpula de oficiais do Exército brasileiro não apresentava uma opinião homogênea acerca desta questão, e que, portanto, não é possível se afirmar que ela tenha sido vista apenas como uma forma de se marginalizar a instituição militar dentro do cenário político nacional. Conforme procuramos demonstrar, este processo também pode ser visto por um outro ângulo, já que foi concebido de forma bastante otimista por um grupo de oficiais de orientação política liberal moderada, que acreditavam que a redução dos efetivos militares seria capaz de interromper a partidarização e insubordinação das tropas, instaurada desde o 
período da Abdicação de Dom Pedro I. Ainda nesta direção, acreditava-se que a criação desse núcleo militar pequeno, mas bem organizado, permitiria a ruptura com vários aspectos próprios do Antigo Regime Português, desencadeando, dessa forma, um processo de nacionalização e profissionalização das tropas. Portanto, observa-se que a alta cúpula militar era composta de grupos e interesses diferentes, o que certamente contribuiu para que o processo de desmobilização das tropas de terra fosse encarado de modos igualmente diferentes ao longo do período regencial. 